\title{
Expression of Concern: Assessing the suitability of hybridizing the Cuckoo optimization algorithm with ANN and ANFIS techniques to predict daily evaporation
}

\author{
Jamshid Piri $^{3} \cdot$ Kasra Mohammadi $^{2} \cdot$ Shahaboddin Shamshirband ${ }^{1} \cdot$ Shatirah Akib ${ }^{4}$
}

Published online: 20 December 2018

๑) Springer-Verlag GmbH Germany, part of Springer Nature 2018

\section{Expression of Concern: \\ Environ Earth Sci (2016) 75:246 \\ https://doi.org/10.1007/s12665-015-5058-3}

The Editors-in-Chief of Environmental Earth Sciences are issuing an editorial expression of concern to alert readers that the original article shows substantial indication of irregularities in authorship during the submission process. The authors suggested peer reviewers whose identity was not possible to verify. This article contains overlap with Piri et al. (2015) and Valian et al. (2013) (amongst others). All authors disagree with this editorial expression of concern.

\section{References}

Piri J, Kisi O (2015) Modelling solar radiation reached to the Earth using ANFIS, NN-ARX, and empirical models (case studies: Zahedan and Bojnurd stations). J Atmos Solar Terr Phys 123: 39-47. https://doi.org/10.1016/j.jastp.2014.12.006

The original article can be found online at https://doi.org/10.1007/ s12665-015-5058-3.

Shahaboddin Shamshirband

shamshirband@um.edu.my

Kasra Mohammadi

kmohammadi@umass.edu

1 Department of Computer System and Technology, Faculty of Computer Science and Information Technology,

University of Malaya, 50603 Kuala Lumpur, Malaysia

2

Department of Mechanical and Industrial Engineering, University of Massachusetts, Amherst, MA 01003, USA

3 Department of Water Engineering, Soil and Water College, University of Zabol, Zabol, Islamic Republic of Iran

4 School of Energy, Geoscience, Infrastructure and Society (EGIS), Heriot-Watt University Malaysia, Putrajaya, Malaysia
Valian E, Tavakoli S, Mohanna S, Haghi A (2013) Improved cuckoo search for reliability optimization problems. Comput Indus Eng 64:459-468. https://doi.org/10.1016/j.cie.2012.07.011

Publisher's Note Springer Nature remains neutral with regard to jurisdictional claims in published maps and institutional affiliations. 